\title{
Prospects for the Development of a Universal Theory of Truth
}

\author{
Nikolay N. Gubanov \\ Bauman Moscow State Technical University \\ 5/1, 2nd Baumankaya Str. \\ Moscow, Russia 105005 \\ E-mail: gubanovnn@mail.ru
}

\author{
Nikolay I. Gubanov \\ Tyumen State Medical University \\ 54 Odesskaya Str. \\ Tyumen, Russia 625023 \\ E-mail: gubanov48@mail.ru
}

\author{
Lyudmila Rokotyanskaya \\ Bauman Moscow State Technical University \\ 5/1, 2nd Baumankaya Str. \\ Moscow, Russia 105005 \\ E-mail: lo_rokotyanskaya@rambler.ru
}

\begin{abstract}
Some philosophers are unjustified in their attempts to remove the category of truth from philosophy and science and to replace it with the concepts of sense, validity, and plausibility. This paper considers classical and nonclassical concepts of truth. The paper aims to substantiate the hypothesis about the possibility of synthesizing rational features of existing concepts and creating a universal (general) theory of truth. This theory can be built on the concept of correspondence, since only here the essence of truth is defined as knowledge corresponding to reality. Other concepts reflect, with varying degrees of accuracy, different characteristics of true knowledge, the conditions for its acquisition, justification, acceptance in the scientific community, functioning, use, and in some cases equate the essence of truth with its criterion. Five criteria of truth are distinguished: empirical confirmation (leading criterion); logical provability; heuristicity of hypotheses; simplicity; and beauty.
\end{abstract}

Keywords-truth; paradoxical self-reference; concepts of truth; universal concept of truth; truth criteria; empirical verification

\section{INTRODUCTION}

From the very beginning of philosophy, the category of truth was one of its most important ones. Pythagoras, who is credited with the very term "philosophy", back in VI BC argued that some are born greedy for fame and gain, while philosophers only seek truth [1]. Two and a half millennia later, in 1928 , one of the most prominent scientists of the $20^{\text {th }}$ century. Reichenbach considered the most important goal of the scientific philosophy to be the establishment of the concept of objective truth as the highest criterion of philosophical cognition [2]. Thus, for more than two and a half millennia, philosophy focused on comprehension of truth. However, at present time the category of truth is questionable and some philosophers no longer seek truth they tend to reject this category.
This rejection manifests itself in different forms. A.V. Pavlov believes that truth in liberal arts has a creative, historically and regionally changing nature and is often defined by weaker concepts of validity, verity and plausibility [3]. Still, he does not explain how they are different from truth. V.M. Pivoyev notes that for natural and technical sciences, truth is an important characteristic, but for social and human sciences, because of subjective interests of individuals and the masses, the category of truth is not fully applicable, since it acquires a subjectively-estimated subtext, so it is more appropriate to use the category of validity [4]. The definition of validity is not provided.

There is also a cardinal position. It acknowledges that the category of truth has lost its meaning and must be eliminated not only from philosophical, but also from scientific knowledge. This position is held by such postmodernist philosophers as Rorty, Derrida and others [5]. Some Russian authors also share this position. The Epistemology \& Philosophy of Science journal conducted a panel discussion to justify the need to replace the category of truth in science with the concepts of sense and plausibility. This viewpoint was upheld by L.A. Markova, A.P. Ogurtsova, and Yu.S. Morkina [6]. However, representatives of special sciences will never support this position. Scientists have sought and will always be seeking truth. It is no coincidence they were called knights of truth since ancient times. We agree with F.A. Selivanov [7], G.D. Levin [8] and other authors that the category of truth still remains the central category of epistemology, essential and irreplaceable by any other concept of science.

\section{PERSPECTIVES OF SYNTHESIZING VARIOUS THEORIES OF TRUTH}

S.A. Lebedev, basing on his profound investigation of the problem of scientific truth, singles out the following theories: the correspondence (Aristotelian) theory, where truth is the 
correspondence of the content of knowledge about the object to the object itself; the coherence theory, where truth is the logical correspondence of some statement to other statements accepted as true; the convention theory, where truth is a conditional agreement on the appropriateness of some statement to its subject; the pragmatic theory, where truth is a theory, a concept that brings benefit or success; the instrumental theory, where truth is knowledge: a description of the sum of operations leading to the achievement of a goal or the solution of a problem; the consensus theory, where truth is the result of long cognitive communications to reach consensus among members of the scientific community and recognize knowledge as true; the intuition theory, where truth is the intuitively clear knowledge not requiring empirical justification or proof; the empirical theory, where truth is either fixation of observation, or knowledge whose consequences are confirmed by observation and experiment; the psychological theory, where truth is the knowledge whose validity is credited by scientists [9].

Lebedev justifiably believes that the main objective reason for the ambiguity of the problem of truth is the qualitative diversity in various types of scientific knowledge. In his opinion, each of the concepts reflects a certain real aspect of the scientific cognition [10]. Is it possible to create a universal, general theory of truth? Apparently, it is possible. A qualitative variety of cognitive processes and the need for their comprehension is not the unique, but a typical cognitive situation, determined by the dialectic of the individual and the general. In all spheres, knowledge transits from knowledge of the individual to knowledge of the general. For example, there exist numerous energy processes, but there is a general concept of energy. It is the same everywhere. Therefore, a general understanding of truth is possible. Otherwise, we would pass to the positions of epistemological nominalism: there are separate cognitive processes, but a general concept of truth is impossible. Apparently, the general theory of truth has not yet been created because of the extreme complexity and diversity of cognitive processes.

What can this general, or universal, theory of truth be like? Our hypothesis is as follows. The core of the general theory of truth can be the correspondence concept, since only this concept clarifies the essence of true knowledge. Descartes formulated the main idea of the correspondence theory in a clear and concise manner: truth is the correspondence of thought to the subject [11]. Other concepts, with varying degrees of accuracy, disclose different characteristics of true knowledge, the conditions for its acquisition, justification, acceptance by the scientific community, functioning, use, and in some cases equate the essence of truth with its criterion.

True knowledge must involve information about a certain reality external to human consciousness. Knowledge, limited in itself and irrelevant to reality, cannot possess truth. Consequently, we believe that only the correspondence theory reveals the essence of truth. True knowledge is always knowledge about a particular subject, and not just any knowledge. If there is no correlation with the subject, then the category of truth has no meaning. There is no objectless truth and no true knowledge about nothing [12].
Truth is always represented by the correspondence of knowledge to its subject, that is, the part of the reality with which the cognizing subject interacts. Truth, subjects and objects of cognition in the philosophical and social sciences possess peculiar characteristics. Compared to objects of natural sciences, their degree of uniqueness is more pronounced, they are very complex and changeable, they include subjective reality without physical properties mental in its character [13]. Still, these features can be taken into account while adhering to the interpretation of true knowledge as correspondence.

In the $20^{\text {th }}$ century the theory of correspondence faced serious difficulties and was rejected by a number of scientists and philosophers. One of the difficulties is related to the nature of the object of study in quantum mechanics: this object is not natural existing only under experimental conditions, for example, flow of elementary particles. Thus, a complex problem arises: can the knowledge obtained in the experiment be related to the surrounding reality? This knowledge could rather be attributed to constructed, but not objective reality, and the correspondence of this knowledge to objective reality does not make sense. The conclusion is plausible, but not accurate. In non-classical physics, cognition becomes more complicated: first, correlation of knowledge with an empirical object and, secondly, its correlation with disciplinary ontology, that is, with the physical picture of the world. The procedure of "inserting" knowledge about an empirical object into a disciplinary ontology is very complicated $[14,15]$.

The theory of correspondence faced insecurity when quantum mechanics, cosmological theories, theories of the origin of life etc. became unable to correlate knowledge to the subject and to achieve direct empirical verification of hypotheses. However, the absence of empirical evidence does not mean that the correspondence theory is wrong, if anything, it means that empirical evidence has not yet been found. All scientists persistently search for these evidence and sooner or later find them. Let us look at a well-known example. In the first half of the $19^{\text {th }}$ century there were hypotheses about the chemical composition of the Sun. But no one could even imagine how to verify these hypotheses because of the 150 million $\mathrm{km}$ distance to the Sun and its enormous temperature. Comte argued that the chemical composition of the Sun and the stars was and would remain unknown. Comte's statement seemed irrefutable. But in 1859 Kirchhoff and Bunsen invented spectral analysis, which helped determine the chemical composition of the Sun. Helium was discovered on the Sun in 1868, whereas on Earth it was discovered only in 1895 . We cannot predict the scientific and technical discoveries in principle, for they would cease to be discoveries. We can only extrapolate the existing trends. Therefore, we can set no limits in understanding the world, including empirical verification of hypotheses, because we do not know what science and technology can achieve in the future.

Let us look at the possible correlation of the correspondence theory with other theories in more detail. In the coherence concept, truth is understood as knowledge consistent with other knowledge. Being true means being an 
element of a consistent knowledge system. Thus, the coherence concept separates itself from the object of truth and therefore does not disclose the essence of truth. However, it describes such properties of truth as logical consistency, systemacity, and integrity. These three properties of truth enable a logical criterion of truth: the possibility of proving the accuracy of certain provisions without empirical verification. Therefore, the coherence concept is complementary to the correspondence theory and can contribute substantially to the latter.

Similarly, Bacon's empirical concept also does not explain the essence of truth, but argues that empirical confirmation is a criterion of truth. The convention theory and the consensus theory describe the conditions for the scientific community to accept knowledge as true. It is known that ultimate truth of a theory cannot be verified empirically or theoretically. These concepts can show the circumstances that will interrupt the infinite process of a theory justification and confirm it as true. Thus, consensus in the cognitive debate regarding the acceptance of the heliocentric model of the solar system took about 200 years, non-Euclidean geometry about 50 years, quantum mechanics about 25 years, and the special theory of relativity about 15 years.

In the pragmatic concept, the essence of truth is equated with its criterion, which, moreover, is misinterpreted (goodness is in actions). But the correct interpretation of this concept can help find a rational kernel about the conditions for using scientific knowledge for people's good and not for evil. The instrumental concept can disclose the conditions for using true knowledge for effective theoretical and practical activity. The psychological and intuition concepts could reveal the role of subjective factors - intuition, faith, will - in the generation of scientific truth. But in any case, the essence of truth is the correspondence of knowledge to its subject. Thus, there is a prospect of synthesizing rational aspects of other concepts on the basis of the correspondence concept and creating a universal theory.

\section{The PROBLEM OF TRUTH CRITERION}

The rationalists Leibniz, Spinoza, and Descartes considered truth criterion to be the absence of doubt, obviousness, distinctness and clarity of thought. Undoubtedly, distinctness and clarity are positive qualities in thinking (in comparison with confusion and vagueness), but they cannot be considered truth criteria. Some of the misconceptions can be unquestionable, distinct and clear, for example, the impression of the movement of the Sun around our planet. Pragmatists suggested usefulness as a criterion of truth. Indeed, true knowledge can and will benefit people, but deception can also be useful to someone, even more than truth itself. By the way, this is the reason for deception to exist and spread inexorably.

The followers of the convention and consensus theories viewed truth criterion as an agreement among scientists: truth is the knowledge that scientists agreed to consider true. However, the history of science shows that the agreement of scientists cannot be truth criterion. There were situations in which the majority of scientists recognized true idea as untrue, and vice versa. The agreement cannot be the cause of truth as well. The cause of truth is the correspondence of knowledge to its subject. And if in the course of cognitive negotiations, scientists are convinced about this correspondence relying partly on evidence, partly on faith and intuition, then there is a consensus that this knowledge is true. Consequently, agreement is a consequence of proving the truth of these provisions.

The truth criterion similar to that in the convent theory was recognized by A. Bogdanov and other followers of the validity theory: true knowledge is the one that corresponds to the opinion of the majority. However, validity, like scientific consensus, cannot be truth criterion. It is one of the possible consequences of the true knowledge. It was Descartes who argued that the question of truth is not solved by a majority of votes. The spheres where dogmatic elements are strong often understand truth criterion as the opinion of authority. In these cases, infallibility is unofficially, and in some cases officially, attributed to the leaders, for example, to the Pope. No doubt that opinions of the authority ought to be taken into account, especially by young people. But even the authority, like any other person, may be mistaken.

So, neither distinctness, nor clarity of the thought, nor certainty in its correctness, nor the benefit, nor the agreement of scientists, nor the opinion of the majority of people, nor the authority can serve as truth criteria. Based on the analysis of the scientific knowledge development, and the history of the knowledge development in general, we can conclude that the leading truth criterion is the empirical (experimental) confirmation of hypotheses and theories.

Experience contains observation and practice (lifechanging activity), including scientific practice, or experiment. Apparently it was Bacon who had introduced experience as truth criterion. In particular, he believed experience to be the best of all evidence provided it was based on the experiment [16]. Later various aspects of this theory were developed by Locke, Feuerbach, Marx, Engels, neo-positivist philosophers and most of the Russian philosophers of the 20th century. Empirical verification can have several forms, but its basic element is observation. It must not be a separate, single act, but statistically reliable observation: it removes the impact of random, unforeseen factors, eliminates errors of sensory perception and instrumental errors. There are two kinds of observation as the basic component of truth criterion.

The first is pure observation, which is conducted without intervening into natural processes. An example of such a case is Leverrier's assumption about an unknown planet confirmed Halley's telescopic observation, who discovered it only at 52 minutes' distance from the pre-calculated place. The planet was named Neptune. The other kind of observation is part of the practical activity aimed at transforming existence. Each kind of cognitive activity is characterized by its own kinds of verification as truth criterion. In natural sciences, verification is represented by experiments (of a specific type), industry, technology, agriculture (general species), in medicine by clinical practice 
and partly by experiments, in philosophy by the whole human practice.

Authors who deny the necessity of the notion of truth appeal to the well-known Kantian thesis that a person knows only his perceptions and does not know the objects themselves outside perception. They believe that truth criterion does not exist, since it is impossible to compare an object and knowledge about it. As we know, Hume also believed that this might be the reason why we should not assume that objects exist, there may be no objects at all. However, this argument does not refute the concept of the correspondence of knowledge to an object. We agree that Kant, Hume and many other skeptics and agnostics were right to assume that people do not possess objects, but sensations and perceptions. They were also right about the fact that people cannot directly compare their knowledge with its subject. However, they did not take into account that to do this an individual can use an indirect, experiencemediated method: comparison of two images [17]. A subject studies an object and acquires knowledge about it. It is still unknown whether the knowledge is true. Further on, the subject processes the knowledge according to the laws of logic. This results in a model (image) of the expected phenomena, i.e. ideas about them. After that, the subject compares the existing model of expected phenomena with the perception of real phenomena obtained either through an experiment reproducing the expected phenomena, or by observing the natural course of events (if experiment is impossible or unnecessary). If the two images coincide, the subject assumes that the verified knowledge is true, i.e. it correlates with its object.

Mendeleev discovered the periodic law when studying the properties of chemical elements. Using this law, he predicted three more unknown elements. He also described the properties of these elements. Mendeleev's prediction was fully justified: Scandium, Germanium and Gallium were discovered. How can the coincidence of the predicted phenomena model with the real phenomena image be explained? Only by the fact that Mendeleev had knowledge that corresponded to reality. Since knowledge is true, then the objects of this knowledge exist. Therefore, the coincidence of the expected, mentally modeled results with the empirical verification results confirms truth both of knowledge and the objective existence of the external world.

As regards sensory perception, it is the only direct channel of communication between the human consciousness and the outside world, always involved in the empirical verification of knowledge. Correct (informative, vivid) perceptions confirm the subject feels confident in the environment [18]. If perceptions were incorrect, a person would stumble, get into road accidents, fall into holes in the ground, eat food gone bad, get burnt, etc. Under certain conditions, perceptions become erroneous taking the form of illusions and hallucinations. This becomes obvious when a person loses orientation and is studied by psychiatry.

Thus, empirical verification, being the leading truth criterion concerned with comparing models of expected phenomena with images of real phenomena, serves as an indirect method of comparing knowledge with reality. The humankind has no other method; such is the nature of our knowledge. And if someone is not happy about this, "it cannot be helped". Fortunately, outstanding scientific discoveries and the whole history of science demonstrate that this circumstance cannot be regarded as an insurmountable obstacle for the scientific development. Scientists ignore the agnostics' assumption about the fundamental impossibility of comparing the image and the subject. They use the indirect method of comparison we described above making one triumphal discovery after another.

To some extent, difficulties in verifying the truth of knowledge are overcome thanks to auxiliary criteria. One of them is logical proof. It is related to experimental proof in the following respects: 1) logical evidence is based on assumptions that had been previously confirmed empirically; 2) the result obtained by a logical method can be verified experimentally. Heuristics (the effectiveness of using this knowledge in the subsequent cognitive process), and aesthetic criteria - simplicity and beauty also have some significance.

\section{CONCLUSION}

In conclusion, we can note that there is a fundamental possibility of synthesizing suitable aspects of the existing truth concepts and creating a general theory. The core of such a unified theory can be the concept of correspondence, since it establishes the character of the epistemological connection between the subject and the object. The cognitive process occurs in the subject-object system, even if the object is human-sized, and the sub-object is part of the object. The correspondence concept establishes the correspondence of the subject's knowledge to the object as true. This correspondence is verified empirically, which serves as an indirect way of comparing knowledge with reality by comparing two images: expected and real phenomena. Thus, any scientist uses the concept of correspondence explicitly or implicitly. We can see the implicit use of the correspondence concept in the scientific qualification process. Any thesis contains the object of research and the main findings/ arguments to be defended. The candidate is to show the correspondence of the findings/ arguments to the object of research. This is truth according to the correspondence concept. The best result, apparently, can be a synthesis of the correspondence concept and the coherence concept. The former discloses the essence of true knowledge, and the latter discloses its structure and system. Other concepts of truth also contain valuable features, and further research will explore and combine them.

\section{REFERENCES}

[1] Diogenes Laërtius. Lives of Eminent Philosophers. Harvard University Press (Cambridge/London), 1925.

[2] Reichenbach, H. The Philosophy of Space and Time. London. 1957.

[3] Pavlov A.V. Logic and methodology of science. M., Flint, Nauka. 2010. 
[4] Pivoyev V.M. Social and Human Sciences: Specifics and Correlation. // Vestnik Ishimskogo Gospedinstituta im. P.P.Ershova. 2013. № 3. P. 91-101.

[5] Gubanov N.I. Poverty of the philosophy of postmodernism // Philosophy and society. 2007. № 1. P. 54-68.

[6] Markova L.A., Ogurtsov A.P., Morkina Yu.S. Panel discussion // Epistemology \& Philosophy of Science. 2009. V. XXII. № 4. P. 4877.

[7] Selivanov F.A. Goodness, truth, connection. Tyumen. 2008.

[8] Levin G.D. Truth and rationality. M., Kanon +. 2011.

[9] Lebedev S.A. The Reassembly of the Epistemology // Voprosy filosofii. 2015. № 6. P. 53-64.

[10] Lebedev S.A. The Structure of Scientific Rationality // Voprosy filosofii. 2017. № 5. P. 66-79.

[11] Descartes R. Discourse on the Method. Booklassic. 2015.

[12] Ivlev Yu. V., Ivlev V.Yu., Ivleva M.L. Logical-argumentative basics of educational culture // Proceedings of 4th International Conference on Education, Language, Art and Intercultural Communication (ICELAIC 2017) Part of the ASSEHR series. Moscow, Russia. P. 173-177.

[13] Gubanov N.I., Gubanov N.N. The role of mentality in the development of society: sociocultural hypothesis // Vestnik slavianskikh kultur-bulletin of slavic cultures-scientific and informational journal. 2017. Vol. 43. № 1. P. 38-51.

[14] Oseledchik M.B., Ivlev V.Yu., Ivleva M.L. The fractal nature of implicit knowledge // Proceedings of the 3-rd International Conference on Arts, Design, and Contemporary Education. (ICADCE 2017). Advances in Social Science, Education and Humanities Research. Paris: Atlantis Press, 2017. V.144. Pp. 673-676.

[15] Gubanov N.I., Gubanov N.N. Course of lectures in philosophy of science // Herald of the Russian Academy of Sciences. 2015. V. 85. № 10. P. 946-948. DOI: 10.7868/S0869587315100059

[16] Bacon, F. Novum Organum: or, True Suggestions for the Interpretation of Nature Sagwan Press. 2015.

[17] Gubanov N.I., Gubanov N.N. Subjective reality and space // Voprosy filosofii. 2015. №. 3. P. 45-54.

[18] Tsaregorodtsev G.I., Gubanov N.I. Principal grounds for the existence of adequate and sign reflection on the sensory stage of cognition // Bulletin of the Academy of Medical Sciences of the USSR. 1978. № 4. P. 64-70. 